\title{
Reduction of carbon dioxide by bio-façades for sustainable development of the environment
}

\author{
Hamidreza Rezazadeh $^{1^{\dagger}}$, Zahra Salahshoor ${ }^{2}$, Ferial Ahmadi ${ }^{3}$, Farshad Nasrollahi ${ }^{1}$ \\ ${ }^{1}$ Faculty of Architecture and Urbanism, Art University of Isfahan, Isfahan, Iran \\ ${ }^{2}$ Faculty of Fine Arts, Department of Landscape Architecture, University of Tehran, Tehran, Iran \\ ${ }^{3}$ Faculty of Art and Architecture, University of Mazandaran, Babolsar, Iran
}

\begin{abstract}
Nowadays, air pollution and consequently global warming are the major problems that the earth is faced with. These issues can influence climate change and human health. Building façades can play a significant role in the air quality of the urban environment. Therefore, this study draws upon the ability of nature in controlling carbon dioxide to compare three types of bio-façades (i.e. Water façade, Green façade, and Microalgae façade) and to identify an appropriate one. For this purpose, we analyzed documents and scientific literature qualitatively. Then, we identified the aforementioned types of biological façades and selected the most optimal one through the comparison. Additionally, for this comparison, the analytical hierarchy process (AHP) method was employed that resulted in achieving the higher scores by the microalgae façade among other bio-façades mentioned above. The major criteria considered for the AHP analysis included climatic, economic, architectural, environmental, and structural aspects of using the noted bio-façades in buildings. It should be emphasized that the environmental aspect was obtained as the most influential criterion among others. Finally, some technical tips and design requirements for bioreactors are depicted and discussed along with their upcoming challenges and future research direction.
\end{abstract}

Keywords: Bio-façade, Bioreactor, Carbon dioxide reduction, Green Wall, Microalgae

\section{Introduction}

Nowadays, the environmental issues receive as much attention as the economic aspect of the development programs of different countries. As there is a close relationship between the environment and humans, the programs of most countries revolve around environmental issues. The development of technology in developed countries and the formation of environmental protection movements have encouraged such countries to prioritize environmental protection in their macro policies [1]. The reason is that human beings have felt the danger posed by environmental problems and realized that it has compromised their life securities and jeopardized their existences. Environmental pollution, as one of the main environmental problems, is a global issue and has not been limited to either a country or a specific area. It comprises a wide spectrum of matters, of which air pollution may be regarded as the most important one.

Air quality can be identified via measuring the air pollution.
Urban air generally contains significant amounts of pollutants that can endanger human health tremendously [2]. According to the World Health Organization (WHO), the death toll caused by air pollution would be equivalent to $6 \%$ of all deaths [3] which is the fifth leading cause of human death [4]. Air pollution also has a detrimental effect on human health and imposes both the direct and indirect costs on the economy and society. Controlling air pollution can cut down those costs and unlock financial potentials for sustainable development in this regard [5]. Therefore, combating the air pollution has been one of the major concerns of governments and has involved different organizations and institutions.

The construction sector and its associated industries are the most energy-consuming and polluting industries in the world. This sector consumes about $40 \%$ of the world's energy and emits $30 \%$ of the gases to the atmosphere, which is expected to double in the next twenty years [6]. Therefore, cities with air pollution should work towards a suitable solution to control this problem and reduce its effects. Air pollution management programs have been mainly

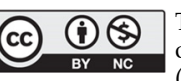

This is an Open Access article distributed under the terms of the Creative Commons Attribution Non-Commercial License (http://creativecommons.org/licenses/by-nc/3.0/) which permits unrestricted non-commercial use, distribution, and reproduction in any medium, provided the original work is properly cited.

Copyright (C) 2022 Korean Society of Environmental Engineers
Received October 19, 2020 Accepted February 28, 2021

${ }^{\dagger}$ Corresponding author

E-mail: H.Rezazadeh@aui.ac.ir

Tel: +98-71-32303871

ORCID: 0000-0002-2009-3473 
focused on controlling pollutant sources [7]. The strategy of reduction in the number of new pollutants entering the air may be ineffective for pollutants existing in the air [4]. New approaches can cut down air pollution to an acceptable level and be effective in eliminating air pollutants. Since, in particular circumstances, the nature has been able to address its problems optimally and sustainably, we would arrive at optimal solutions for absorbing air pollutants by studying the nature.

One of the noteworthy approaches in the field of architecture and urban planning is using nature as a model and developing nature-inspired strategies for mitigating environmental problems. Architecture can improve the quality of life by contributing to sustainable development goals, for instance, declining energy consumption, reducing air pollution, and transforming its elements and organs to micro-living systems. Inspired by sustainability and liveliness of nature, some researchers propose living walls and bio façades for combating air pollution problem. Thus, we may highlight the mission of architects and urban designers as a smaller community in tackling this issue. The aforementioned façades can enhance the energy efficiency of the building and improve air quality significantly. The main point is that structures of these façades are nature-driven.

This review examines the ability of nature-driven strategy implemented in those façades in controlling carbon dioxide. Moreover, it evaluates and compares the performance of three types of biological façades (i.e. Water façades, Green façades, and Microalgae façades) in reducing air pollution, and tries to propose the most suitable and optimal choice. This research also attempts to understand how bio façades used in urban space and architecture can absorb and reduce air pollution, specifically carbon dioxide. In other words, how these façades can effectively contribute to air purification. The literature showed that the most conducted researches on the air pollution issue have focused on controlling pollution sources [7]. Furthermore, according to Schnelle and Brown study [7], it seems that the existing pollutions have been overlooked. The current research addresses the noted gap by formulating two sub-questions and presenting one of the newest solutions inspired by living and sustainable nature.

A) What are the different types of bio façades? And how do they reduce air pollution in a sustainable manner?

B) Due to the urgency of the pollution problems in today's society, what type of biological façade can absorb air pollutants as fast and efficiently as possible? Which type of biological façade is the most suitable?

\section{Material and Methods}

This bibliographic study adopts an applied research design and is descriptive-analytical. Due to the nature of the study, we analyzed documents and scientific literature qualitatively. Then, we identified three types of biological façades and selected the most optimal one through the comparison. Finally, we explained technical tips and design requirements for bioreactors and discussed their upcoming challenges and future research direction of the bioreactor systems.

\section{Theoretical Foundations and Approaches}

\subsection{Interaction of Nature with Architecture to Control Carbon Dioxide}

So far many studies have proposed different methods for carbon dioxide absorption and reduction [8-12]. All methods used for absorbing carbon dioxide fall into biotic and abiotic categories. In the abiotic method, carbon dioxide is absorbed by physical and chemical changes through engineering techniques. Conversely, in the biotic method, carbon dioxide is absorbed by natural elements such as water, plants, or microorganisms. The main advantage of the abiotic method is its high speed in controlling the amount of carbon dioxide. One of the major disadvantages of this method is the use of chemicals that harm human health. Comparatively, in the biotic method, the rate of carbon dioxide absorption and control is low; this inexpensive method is useful for other environmental processes [8]. For instance, it has a minimal effect on human health and does not require special technology [8]. That is why using biotic methods should be given priority in reducing environmental pollutants. So far, several biotic methods have been proposed for the absorption of carbon dioxide. In the following section, we explain the most important ones (Fig. S1).

A) Absorption of carbon dioxide by oceans: In this method, carbon dioxide is sent to the habitat of phytoplankton in the depths of the oceans. Using their photosynthetic ability, these organisms can absorb carbon dioxide.

B) Absorption of carbon dioxide by the soil: In this method, the collected carbon dioxide is injected into the deep layer of the soil. In addition to absorbing carbon dioxide, this method has many advantages, for instance, it can improve the quality of soil and groundwater, restore degraded ecosystems, and increase agricultural yields.

C) Absorption of carbon dioxide by forests (trees): Forests are known as the largest natural carbon dioxide absorbers. Any plant capable of photosynthesis can also absorb carbon dioxide. Among these plants, single-celled plants such as mosses, lichens, and microalgae perform better than the organic plant species in absorbing carbon dioxide because of their simple structure and high surface-to-volume ratio. Among the mentioned cases, the absorption of carbon dioxide by plants is the fastest, most stable, useful, and economical method [12].

\subsection{Water Façade: Using Water in the Outer Shell of the Building}

The idea of using water to absorb air pollutants comes from the purification of the air by rain. During rain, water droplets purify the air by absorbing air pollutants and fine dust, and by dissolving them in themselves [14]. Apart from the practicality of water walls or curtains, they can contribute to the removal of pollutants and air conditioning (Fig. 1). Though this purification system gained popularity for its aesthetics aspect, it suffers from some limitations. According to some limitations regarding water freezing and evaporation of water in cold and hot climate regions, respectively, this system could not contribute to controlling 

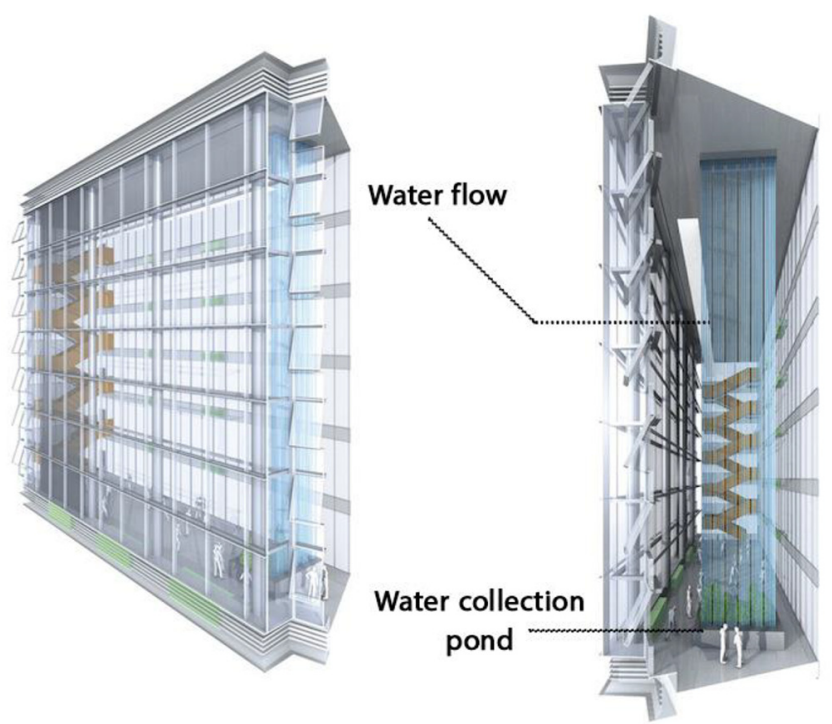

Fig. 1. Water façade [15].

air pollution consistently [15]. Also, due to water shortage problems in most countries, and its high cost of operation, using this system is not rational. The façade materials are at the risk of being eroded by the salts in the water. Other disadvantages of using this system include the impossibility of its implementation in all climates, lack of its adjustability with all seasons, a limited radius of impact, increased water consumption costs, and the possibility of water freezing in cold seasons [4].

\subsection{Green Façade: Using Plants on the Façade of the Building}

Using plants on a small and large scale can have significant effects on air pollution. However, planting trees in densely populated cities is not always possible [16]. For that reason, using green façades is one of the most popular and common ways to absorb air pollution in cities because they can be added to existing or under construction buildings and fit in the limited space. In addition to absorbing pollutants from the air, this system has other advantages. For instance, it can improve the thermal performance of the building by insulation (reducing energy costs), air quality, urban ecosystems, surface water in the city, food production, the aesthetic of urban landscape, people's health, and sense of satisfaction and comfort. It can also reduce greenhouse gases, heat islands, noise pollution [17-24]. Despite the acceptable performance of this system, it has some deficiencies. For instance, there is a limitation for selecting plant species appropriate to the climate of the region [25]. There is a possibility of uncontrollable plant growth [26] and wall destruction [27, 28]. The costs of installation, operation [21], and maintenance [29] are high. Supplying water at heights is a problem [30]. There is limited space for the growth of the plants' roots [25]. The high weight of the system imposes the extra load on the building body [31] Materials of these systems can negatively influence the environment [32] and create a suitable environment for the growth and nesting of some insects and vermin [33].

Addressing the problems and limitation of two systems reviewed, we need to find a new solution which can reap the benefits of water, plants, and green cover. One of the most modern solutions is the use of air-absorbing microorganisms in the building walls. One of the most common and efficient organisms is photosynthetic microalgae, which have a very high efficiency compared to ordinary plants. The use of microalgae in the façade of the building is a solution that benefits from the combination of previous systems, namely water, and plants at the same time.

\subsection{Microalgae Façade}

Microalgae are the simplest forms of plants (without roots, stems, leaves, and other plant organs) (see Fig. 2). These species of living microorganisms are mainly single-celled [34-36]. Due to the high surface-to-volume ratio, compared to organic plant species, they have a very high ability in absorbing and reducing carbon dioxide [37]. Microalgae produce about 60 to 75 percent of the oxygen needed by humans and animals through absorbing carbon dioxide from air or water during photosynthesis (more than all forests and greenies on Earth) [38, 39]. In the process of absorbing carbon dioxide and emitting oxygen, microalgae produce a kind of green biomass and nutritious protein [38]. Microalgae are also 10 times more photosynthetic than adult trees and grass. To produce $1 \mathrm{~kg}$ of micro-algal biomass, they need to absorb $1.8 \mathrm{~kg}$ of carbon dioxide [40].

These organisms do not need clean water and can grow in all aquatic habitats such as brackish water, sewage water, and tap water. Sewage water is the best environment for the cultivation of microalgae because they get most of their nutrients from wastewater [41]. As building walls consist of large surfaces exposing to polluted air, integrating microalgae with building façades in the form of biological façades can turn the walls into photosynthetic surfaces. That way, they can enhance the passive thermal performance of the building in response to climate change and transform an ordinary building into a healthy and vibrant building [40]. It can also turn the building walls into a power plant [42]. Integrating microalgae with the façade of the building requires a water storage tank and cultivation. Therefore, examining the feasibility of integrating a suitable species of microalgae with the cultivation system is important, and evaluating their attachment ability to the building façade is necessary. Microalgae have been cultivated at a small scale as a food source in Africa, Asia, and North and Central America for many years $[38,39]$ but producing microalgae in large quantities requires a suitable system. Today, bioreactors are the most common and optimal systems for microalgae cultivation [43]. There are two types of bioreactors for microalgae production: 1- open system (pond), 2- closed system [39]. An open or pond system is the most common method of microalgae cultivation worldwide (Fig. S2). Despite the production of large volumes of biomass [44], low cost in the construction of this system, and the ease of operating this system [45], its efficiency is very low [39]. Problems of this system include the occupation of large-scale land, risk of contaminating microalgae culture medium by polluted air [43, 45], or contaminated and harmful heavy metals, parasites, insect larvae, and unwanted microalgae species. Other problems are vanishing pond water to a large extent through evaporation, limitation of light infiltration into the depths of the pond and lack of equal distribution of light, 

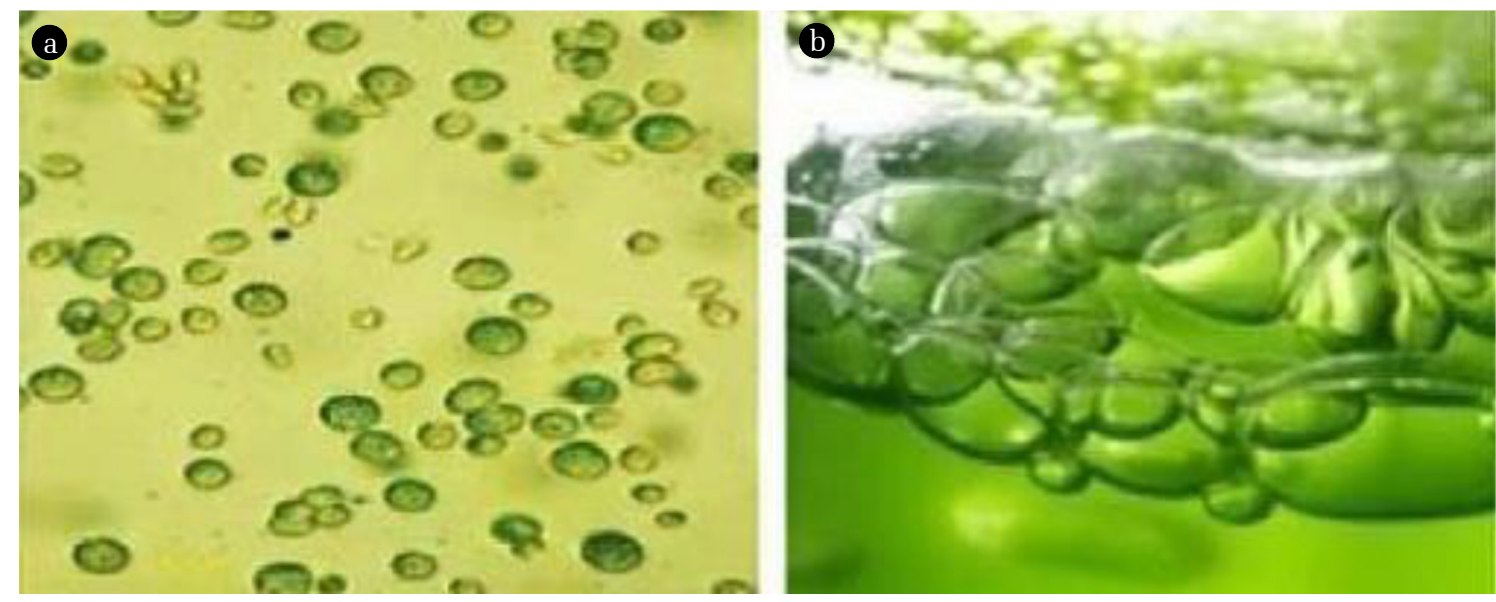

Fig. 2. Microalgae and the ability to absorb more carbon dioxide than organic plants [40].

difficulty in controlling and protecting the culture medium [39, 46-48]. Therefore, due to the mentioned problems, this type of system cannot be integrated with the building. Also, the process of microalgae growth and changes they make in the appearance of the culture medium and the building façade are among the concerns of the urban area. This issue can cause variability and dynamism in the urban landscape. Therefore, to overcome the mentioned disadvantages, closed systems can be used to accurately control the parameters and environmental conditions on the microalgae.

\subsubsection{Closed photobioreactor}

This system is used to address the problems of the open system. So far, various methods and approaches have been proposed for microalgae production, but very few of them can be mass-produced and industrialized [40]. In a closed system, the surface-to-volume ratio is the most important principle for the production of microalgae in large quantities. The appropriate ratio depends on the uniform and optimal distribution of sunlight through the culture medium. This feature can improve the photosynthesis process. Therefore, the shape and geometry of the bioreactor have a significant effect on the light distribution and system efficiency [49]. Since this study attempts to provide a suitable bio-façade which can be easily attached to building façades, the plate bio-reactor system with a suitable geometry and high surface-to-volume ratio can serve this purpose and be used for the construction industry.

The plate bioreactor (Fig. 3) is usually made of clear transparent glass, Plexiglas, polycarbonate, or polyethylene [11, 50, 51]. According to available studies, the thickness of $15 \mathrm{~mm}$ is suitable for the reactor because it let the light pass through the microalgae culture and covers a wide spectrum; therefore, no area would stay in the dark [52]. The optimal thickness for bioreactors is estimated to be 5 to $6 \mathrm{~cm}$ [51]. Apart from the light, the growth rate of microalgae is directly dependent on the mixture of culture medium [53]. As the plate bioreactor can contribute to the natural composition of the culture medium by emitting air bubbles at the bottom of the panel and preventing the accumulation of dissolved oxygen, it has a good performance [53].

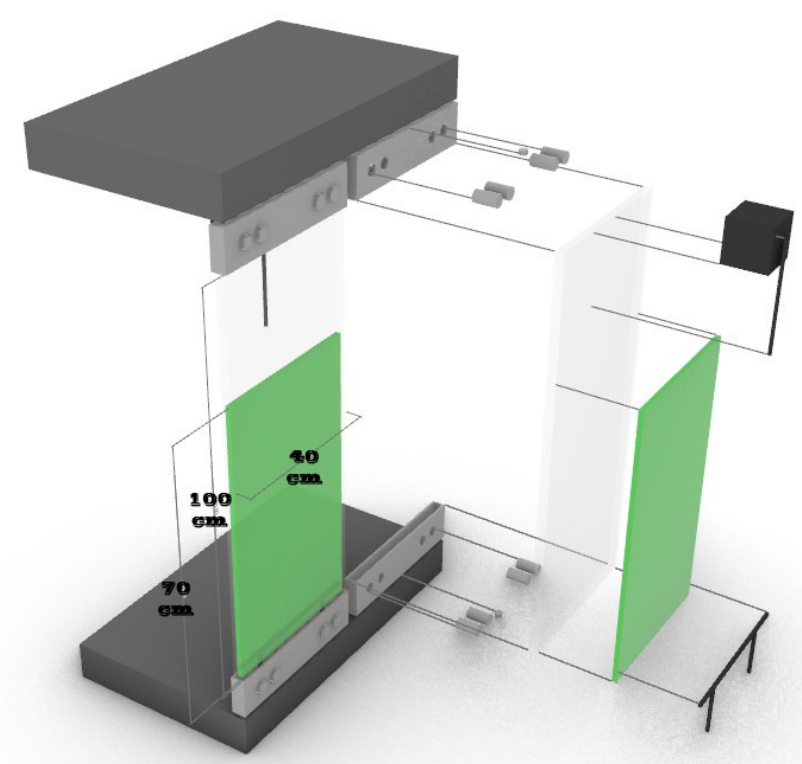

Fig. 3. A plate bioreactor with technical details [54].

The structure of the plate bioreactor is not capable of withstanding high pressures (pressure due to the large volume of liquid inside the panel). Since the growth of microalgae is affected by increasing pressure, there are some limitations on raising the scale of this system [11]. However, if it is necessary, this bioreactor can be made in larger sizes using special and reinforced materials such as laminated glass (reinforced glass).

The orientation to the sun's rays in this system is one of the important factors for their absorption. For the optimization of the system, Sierra et al. [55] recommend the east-west orientation for places with the latitudes above 35 degrees and the north-south orientation for the latitudes below 35 degrees. Additionally, this study was conducted in Almería, Spain, 36 $48^{\prime} \mathrm{N} ; 2^{\circ} 54^{\prime} \mathrm{W}$ in 2007. Also, in a study conducted by Slegres in Wageningen University located in Netherland in 2014, the ratio of the orientation of plate bioreactors at the higher latitudes (east-west) to the orientation 
Table 1. Designing Principles of a Plate Bioreactor for Attachment to a Building Façade

\begin{tabular}{|c|c|}
\hline \multicolumn{2}{|c|}{ Designing principles of a plate bioreactor } \\
\hline Orientation & $\begin{array}{l}\text { Selecting the orientation depends on the angle of the sun at different latitudes. However, the } \\
\text { south orientation is suitable for the integration of bioreactors with the building façade }[12,55-56 \text {, } \\
58] \text {. }\end{array}$ \\
\hline Thickness of the panel & The thickness of the panel should not exceed 5 to $6 \mathrm{~cm}$ [51]. \\
\hline Materials needed & $\begin{array}{l}\text { Different types of glass and plastic models (laminated glass, Plexiglas, polyethylene, clear acrylic, } \\
\text { clear polycarbonate, and ETFE) [11, 50,59-61]. }\end{array}$ \\
\hline Temperature & $\begin{array}{l}\text { The optimum temperature for the growth and development of microalgae is } 20 \text { to } 30 \text { degrees } \\
\text { Celsius. Microalgae growth stops at temperatures below } 5^{\circ} \mathrm{C} \text { and above } 35^{\circ} \mathrm{C}[41,50] \text {. }\end{array}$ \\
\hline Light & $\begin{array}{l}\text { Light is one of the important factors contributing to the growth and development of microalgae. } \\
\text { In the absence of natural light, optical fibers and LED lights can be used inside the culture medium } \\
\text { to provide their access to light }[49,58] \text {. }\end{array}$ \\
\hline Carbon dioxide & $\begin{array}{l}\text { To produce } 1 \mathrm{~kg} \text { of microalgae biomass, about } 1.8 \mathrm{~kg} \text { of carbon dioxide is needed. Numerous } \\
\text { sources can be used to supply carbon dioxide }[12,41,43,38] \text {. }\end{array}$ \\
\hline Nutrients required by microalgae & $\begin{array}{l}\text { Nitrogen and phosphorus are essential for the growth and development of microalgae. These } \\
\text { nutrients can be obtained from chemical fertilizers, fish ponds, or wastewater (building wastewater, } \\
\text { animal wastewater, wastewater of factories and industries) [12, 41, 43]. }\end{array}$ \\
\hline Water & $\begin{array}{l}\text { Any aquatic habitat can be used for growing microalgae, including seawater. For producing one } \\
\text { liter of biofuel through microalgae cultivation Approximately } 0.75 \text { liters of water are needed [ } 41 \text {, } \\
50,62] \text {. }\end{array}$ \\
\hline
\end{tabular}

at the lower latitudes (north-south) made a difference of $50 \%$ in the output of the system [56]. This means that at the high latitudes, the south and southwest orientations are the best axes on which plate bio façades can be integrated with the façade of the building [57]. Compared to flat plate bioreactors, sloping bio façades have a higher energy efficiency because the angle of the panel can be appropriately adjusted to the sun's rays [58]. Despite their efficiency, sloping bio façades are expensive. Moreover, Table 1 is presented as an overview of above noted explanations regarding the design principles of integrating a plate bioreactor to a building façade. These principles comprise orientation, thickness of the panel, materials needed, temperature, light, carbon dioxide, nutrients required by microalgae, and water.

\subsubsection{Advantages and effects of using bioreactors in building fa- çades}

The advantages of using bioreactors in the building façades are as follows: a) producing part of the energy required by the building through biomass, b) controlling the amount of light entering the space, c) controlling vision parameters and view, d) providing thermal and sound insulation, e) improving environmental sustainability, f) reducing overall costs of buildings and their beautification [40].

\subsubsection{Production of the required energy of the building through biomass}

Biomass is a sustainable energy source that can produce other forms of energy such as electricity, heat, and biofuels [63]. Biofuels are a new type of renewable and sustainable energy source that does not affect global warming. Like any other renewable energy source (e.g. solar, wind, etc), biomass effectively prevents the climate from changing because it reduces the need for fossil fuels to a minimum level [40]. Microalgae, as a stable source of biomass production, save $50 \%$ of the $60 \%$ of stored fat in their cells as pure oil and convert it into bioenergy sources [38]. For this reason, microalgae are known as sustainable sources of biofuels that can meet some of the building needs. As the energy consumed in today's buildings comes from long distances, it is expensive. Since microalgae can be produced on-site (e.g. façades and walls of buildings), they can minimize the excessive costs of transporting energy to the building [64].

\subsubsection{Optical function (control of incoming light)}

Since green microalgae can absorb red rays, the bioreactor can also act as a shading device for the building and increase the infiltration of sunlight into space [61]. By increasing the concentration of microalgae in the bioreactor system, infiltrating the light into the space decreases $[57,65]$. Thus, the bioreactor system, which consists of vision and algae zones, can be used for optimizing natural light indoors (Fig. S3). In this system, the sunlight enters the space from the vision zone and illuminates the space, and then the visual connection between the inside and outside of the building is established. Also, as the light passes through the microalgae, the color of the microalgae (usually green) affects the space behind it. To prevent this phenomenon, colored blocking strips can be used inside the bioreactor [60]. In addition to the concentration of microalgae in the bioreactor, its angle and geometry affect the amount and quality of the light passing through and change the intensity of the sunlight [66]. As the concentration of microalgae in the bioreactor increases, the less light can pass through it, and this will result in a greater amount of shadow [57]. Therefore, the orientation and location of bioreactors in the southern front 
of the building will guarantee the highest amount of shading and growth rate of microalgae [61].

3.4.2.3. Controlling vision parameters and overview of the bioreactor As Fig. 4 shows, the integration of the bioreactor with the building façade affects the transparency of the building and the amount of visual communication within and outside of the building. It also adds to the visual and aesthetic aspects of the building [61, 66]. For example, the daily and seasonal color changes of microalgae (as a sign of their growth) create a changeable view of the building. The movement of air bubbles inside the panel adds to the fluidity and dynamics of the bioreactor and makes the building look more attractive. Bioreactors are flexible enough to be installed at any angle to the façade of the building or away from the human vision. This feature helps the residents to gain visual comfort [66].

\subsubsection{Thermal performance of bioreactors}

Absorbing the sun's rays and creating shadows by façade bioreactors can make the interior of the building cooler on sunny days [66, 67], but the amount of shading and cooling of the space is directly associated with the concentration of microalgae [68]. This feature makes the panels a better alternative for the equipment and mechanical devices used for shading [66]. As reported by Sardá and Vicente, absorbing the sun's rays through microalgae for photosynthesis can result in shadowing and reducing air temperature and this consequently insulates the building façade thermally and increases energy saving [69]. Façade bioreactors prevent excessive heat from entering the building in summer and save the heat absorbed in summer to keep the building warm in winter. This process shows the coexistence of the bioreactor with the building [70]. Moreover, Kim in 2013 reported that the thermal conductivity of a microalgal bioreactor was comparable to that of low-emission glass. He also found that the bioreactor had a better performance than the broken glass due to the heat capacity of microalgae and the presence of carbon dioxide [60]. It is worthy to note that this study was conducted in the Naval Research Lab in Washington, DC in the United State. Öncel also acknowledged that the installation of bioreactors in the building façade resulted in thermal comfort because bioreactors served as bio-heat exchangers for regulating the temperature inside and outside of the building. Bioreactors were found to save fuel consumption by $33 \%$ and reduce electricity consumption by $10 \%$ [65]. It is estimated that using bioreactors as thermal insulation in the façade of a building for 6 to 10 years can compensate for all the costs related to the waste of energy [69]. Therefore, bioreactors can reduce not only air pollutants but the energy consumption of the building and provide a sustainable solution in the optimization process.

\subsubsection{Acoustic performance of bioreactors}

As microalgae refract the sound through their physical structure, increasing their concentration enhances the acoustic properties of the bioreactor [69]. However, no research has been done on measuring the absorption of sound by microalgae.

\subsubsection{Environmental sustainability of bioreactors}

Different capabilities of microalgae such as carbon dioxide absorption, wastewater treatment, and oxygen production make them superior to other renewable energy sources [72]. However, the accurate assessment of the extent to which bioreactors absorb carbon dioxide and emit oxygen is difficult because the rate of photosynthesis depends on the species of microalgae, shape, the geometry of the bioreactor (Table 2) as well as place and time [60]. For example, 200 square meters of bioreactor implemented in the façade of the BIQ project, absorbs 6 tons of carbon dioxide annually [40].

\subsubsection{Cost of capital (The initial capital for installation and oper- ation)}

Closed bioreactors can affect the growth of microalgae and increase their productivity by monitoring the parameters carefully. Despite this advantage, the costs of their installation and operation are a major obstacle to the utilization of these systems [49]. This is the primary and significant criterion for the private sector and customers of these systems [65]. The final cost includes the cost of building the system, operating the bioreactor, and keeping the

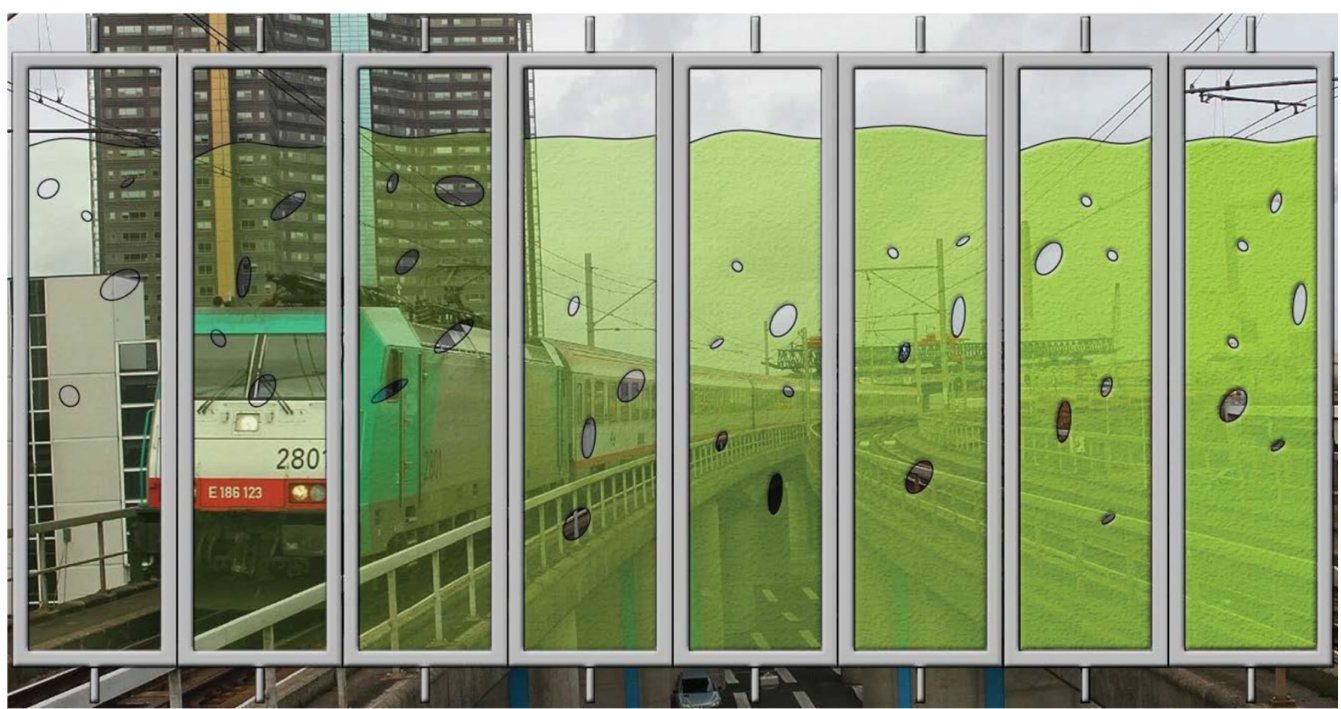

Fig. 4. Changing the transparency of the microalgal panel and its effect on visual communication inside and out [50]. 
Table 2. Common Geometries for Bioreactor Construction

Cylindrical (Column)

microalgae culture medium permanently uniform [39, 69]. The costs of building and installing a bioreactor are higher than those of solar systems or even conventional fuel [69] but the cost associated with bioreactors is declining. According to Schiller, it can be offset by reducing energy consumption and it has long-term benefits for the building and the environment [73]. Even the cost can be compensated in 9 to 13 years depending on the type of bioreactors [69]. Although the cost of a façade bioreactor is much higher than that of the conventional wall [70], it is much lower than other types of façades such as single façades, stainless steel, aluminum curtain walls, stone, and even ceramic façades [69]. Therefore, the coexistence of bioreactors with the building can reduce the cost of both construction and technical operation of bioreactors.

\subsubsection{Aesthetic aspect of façade designs}

The integration of living microorganisms into the walls of the building enhances its aesthetic aspects. The dynamism of the physical structure and chemical function of microalgae can make the dull walls of the building look vibrant [40]. Emphasizing the aesthetic aspect of bioreactors, Genin argues that bioreactors can create attractive and dynamic views that easily attract customers and minimize the cost of construction and system operation in their eyes [74]. According to Fig. S4, the combination of engineering and beautiful designs can result in producing attractive and dynamic bioreactors [67, 69, 74, 75]. This shows that architecture can increase the popularity of bioreactor façades by acting as an interface between technical sciences and design techniques [65].

\subsection{Technical Tips and Design Requirements for Bioreactors and Their Challenges}

In the previous section, we explained the structure, mechanism, and effects of bioreactors. In this section, we explain the technical tips and design requirements for bioreactors and discuss their upcoming challenges and the future direction of research on these systems.

\subsubsection{The necessities and technical requirements for designing a microalgae bio façade}

Table 3 summarizes the inputs and outputs of a building's bio façade and outlines the technical requirements for building a bioreactor. In this table, inputs and outputs required for photosynthetic and solar thermal processes are presented with emphasizing the supplier resources and technical requirements for bio façades where employed in buildings. Overall, the inputs include carbon dioxide, water, nutrients, and microalgae, whereas heats, microalgae biomass, and oxygen are the outputs of those aforementioned processes.

\subsubsection{The most important challenges in integrating a bioreactor with a building façade}

A) Providing adequate and sufficient amounts of nutrients, water, light, and carbon dioxide is a difficult task. Creating a microalgae culture environment, and supplying biomass and product extraction equipment on-site for reducing transportation costs is a challenge.

B) Developing a system (factory) for converting biomass to electricity for use in buildings and operational mechanisms of the bioreactor is expensive. It seems that developing such a system for a small-scale architectural project such as residential buildings is practically unfeasible and has no economic justification.

C) Supplying carbon dioxide and storage equipment for bioreactors integrated with the building is demanding. Although carbon dioxide trappers today can be easily integrated with buildings, their economic viability must be assessed.

D) Supplying delicate, light, durable, easy- to- maintain materials at reasonable costs is demanding [65]

E) Façade bioreactors can produce only $9 \%$ of the total energy required by the building [40]. Therefore, this system cannot supply all the required energy of the building by itself and there is a need for auxiliary systems such as photovoltaic panels and wind turbines.

F) Impacting (limiting) the vision of the building. With the growth of microalgae and increasing the concentration of culture medium, 
Table 3. Input and Output of a Building's Bio Façade and Technical Requirements for Building a Bioreactor

\begin{tabular}{|c|c|c|}
\hline Inputs & & $\begin{array}{l}\text { Supplier resources and } \\
\text { technical requirements }\end{array}$ \\
\hline Carbon Dioxide & $\begin{array}{l}\text { Supplying the required carbon dioxide of microalgae through emitted gases from power } \\
\text { plants, industries, factories, polluted air on highways, etc. } \\
\text { If the source of carbon dioxide is not in the vicinity of the building, the absorption } \\
\text { of carbon dioxide for microalgae would be severely limited. Therefore, it is necessary } \\
\text { and logical to have the source of carbon dioxide production near the project, otherwise, } \\
\text { carbon dioxide must be supplied through the building [76]. Also, equipment such as } \\
\text { a carbon dioxide capture device in combination with the building can solve the problem } \\
\text { of carbon dioxide transfer and storage. } \\
\text { Carbon dioxide trappers require electricity, which can be provided by integrating a } \\
\text { wind turbine with it. In so doing, the required electricity is provided in stably. }\end{array}$ & $\begin{array}{l}\text { - Source of carbon dioxide } \\
\text { emission in the vicinity of } \\
\text { the building or } \\
\text { - Carbon dioxide trappers }\end{array}$ \\
\hline Water & $\begin{array}{l}\text { Any aquatic habitat Microalgae can grow in a variety of aquatic habitat(even waters } \\
\text { that cannot be consumed). The water used in this system can be reused. Therefore, } \\
\text { a closed system of the water cycle can be designed in a bioreactor }\end{array}$ & $\begin{array}{l}\text { - Seawater } \\
\text { - Rainwater } \\
\text { - Saline water } \\
\text { - Salty water and bad taste } \\
\text { - Sewage or contaminated } \\
\text { water }\end{array}$ \\
\hline
\end{tabular}

\begin{tabular}{ll}
\hline Nutrients & $\begin{array}{l}\text { The required nutrients of microalgae can be supplied through the building's wastewater } \\
\text { (The gray and black water of the building). }\end{array}$ \\
\hline Microalgae & $\begin{array}{l}\text { After culturing microalgae in a bioreactor, maintaining it under a controlled temperature - Temperature controlled } \\
\text { until the time of operation is crucial. The exploitation of microalgae (conversion of enclosures } \\
\text { microalgae biomass into oil, electricity, or any other products) can be done both indoors } \\
\text { and outdoors. }\end{array}$
\end{tabular}

\section{Outputs}

Heat Façade bioreactors act as a thermal insulator by converting sunlight into heat. A percentage - Heat exchangers of the heat generated contributes to the growth of microalgae, but excess heat must - Heat storage tanks be absorbed by heat exchangers and be used to heat the building. Excess heat can also be stored in a tank for later use.

\begin{tabular}{|c|c|c|}
\hline $\begin{array}{l}\text { Microalgae } \\
\text { biomass }\end{array}$ & $\begin{array}{l}\text { A refining system such as a centrifuge is essential to extract biomass and other products } \\
\text { from microalgae. Extracted oils are used to produce a variety of biofuels, microalgae } \\
\text { biomass is used to generate electricity in power plants, and residual water is used } \\
\text { in the microalgae cultivation cycle. }\end{array}$ & $\begin{array}{l}\text { - Centrifuge } \\
\text { - Power plant }\end{array}$ \\
\hline Oxygen & $\begin{array}{l}\text { In bioreactors, dissolved oxygen in the culture medium needs to be removed by liquefied } \\
\text { gas devices [77]. Oxygen gas can also be collected by special equipment [78]. }\end{array}$ & $\begin{array}{l}\text { - Liquefied gas device } \\
\text { - Degassing columns and } \\
\text { maintenance tank }\end{array}$ \\
\hline
\end{tabular}

visual communication inside and outside of the building would be limited. Solving this problem requires creating visual areas at the height and determining the angle of human vision in the bioreactor.

G) There is a necessity for using durable materials for installation on the façade of the building to withstand the pressure of the liquid inside the bioreactor in larger scales.

\subsubsection{Future research direction of bioreactors in building façades}

A) Using biological façades (bioreactors containing microalgae), we can be ensured that the air of polluted nodes of cities is cleaned up from harmful carbon compounds and the produced biomass energy is the only source reducing carbon dioxide and emitting oxygen. The result of using this system is having an energy source that does not affect the climate negatively [79].
B) Analyzing all the issues and criticisms regarding the cost of construction and operating bioreactors as bio façades show that the positive contribution of this system in the long run for the building and the environment is justifiable.

C) The use of bioreactors in architecture is not limited to the façades of buildings. Bioreactors can be specially designed as urban furniture such as street art, canopies, and even optical elements (Fig. S5) and be used across the city.

D) Bio façades can be integrated with various types of urban buildings such as office, commercial and residential buildings. Even these façades can be implanted in industrial buildings. The use of these façades in industrial projects is more economically justifiable because by absorbing carbon dioxide produced by industrial activities they also contribute to environmental sustainability [40] 


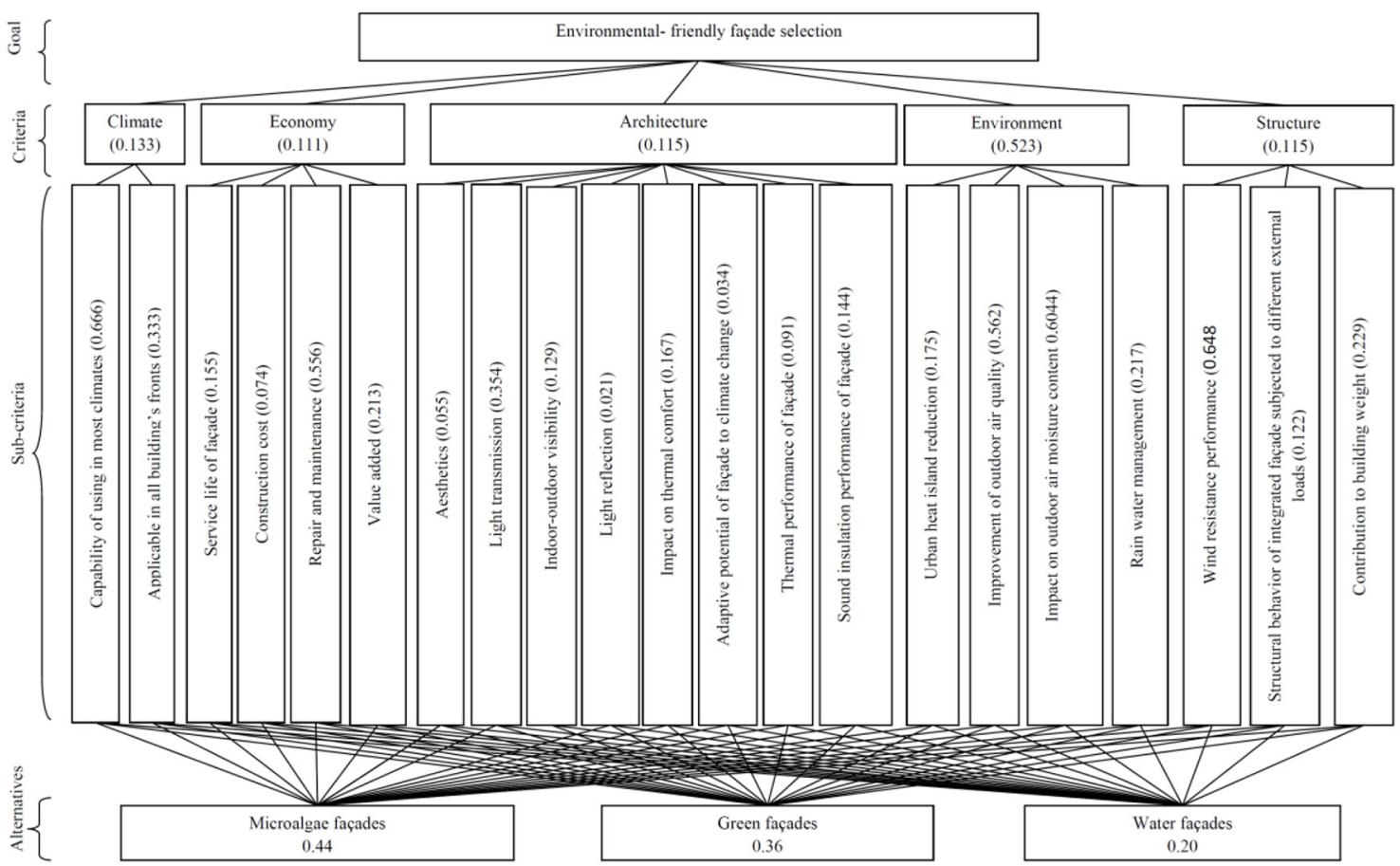

Fig. 5. The AHP model.

E) As biological façades cannot provide all the energy required by the building, it can be concluded that their use is not economically justified at first glance. However, their use can be justified considering their other functions, such as thermal insulation performance for the walls and shading.

F) The integration of the bioreactor with the building helps the building to provide some of its required energy and reduces its dependence on external and public energy sources. Bioreactors also increase environmental sustainability and contribute to sustainable cities by storing excess heat of the sun's rays and treating wastewater.

G) Finally, the integration of bioreactors with architecture ensures a sustainable source of energy at the national level, financial security, a clean and healthy climate, as well as the promotion of symbolic aspects and values of society [80].

\subsection{Selection of the Most Relevant Bio-Façade}

After reviewing different criteria that can significantly contribute to selection of an optimal bio-façade for a building, ranking those criteria is carried out in the following. In addition to comparing the aforementioned criteria, the relevant decision is made through using the analytical hierarchy process (AHP) as one of the multi-criteria decision making approaches. To determine weights and priorities of the noted criteria, they should be compared with each other as well as their sub-criteria through constructing pairwise comparison matrixes. The explaining the AHP method is beyond of the scope of this study, hence for more detailed information regarding the AHP approach, reviewing the studies conducted by Saaty [81, 82] and Saaty and Vargas [83] could be helpful.

It is essential to define principal components of the AHP model implemented in the present research. The alternatives in the decision making problem of selecting the most relevant bio-façade are the water, the green and the microalgae façades. The major criteria considered in this study include climatic, economic, architectural, environmental, and structural aspects of using the mentioned alternatives in buildings. It is noteworthy that all the criteria along with their sub-criteria are shown in Fig. 5. This figure also demonstrates the structure of hierarchy levels (AHP model) applied in selecting the most appropriate bio-façade. The opinions of a group of experts were asked to evaluate the preference of the criteria chosen by the authors as well as the bio-façades (alternatives). This group was comprised of ten university experts who are competent in the field of interest.

In this research, Weighted Geometric Mean Method (WGMM) is employed to reach consensus among judgements made by the experts. Due to assigning the equal weights to all experts, WGMM was simply degraded to the Geometric Mean Method (GMM). Different arguments regarding the implementation of equal weights for such a purpose along with its effects on final decision were discussed in several studies (see [84] for more details).

\section{Results and Discussion}

As earlier noted, the AHP method is employed to choose the proper bio-façade through comparing different criteria as well as their sub-criteria. Afterwards, by using the GMM, the preference scores of all alternatives (the microalgae, green, and water façade) is obtained. In the subsequent, the results regarding the pairwise comparison matrices of major criteria and their associated sub-cri- 
teria are introduced.

All pairwise comparison matrices developed for decision making purpose are presented as Table S1, S2, and S3, in the supplementary material section of the paper. It should be noted that the relative importance (matrix elements) of each factor against each other was assigned using the comparison scale, which is ranged between 1 and 9 values for equal and extreme importance, respectively, suggested by Saaty and Vargas [83]. After constructing these tables, the weight of each criterion, and sub-criterion is determined and the consistency indices (CIs) and the consistency ratios (CRs) are computed based on random consistency ratio (RCI) proposed by the abovementioned studies thereupon. In this regard, all CRs do not exceed 0.1 where it shows that the rating conducted for all pairwise comparison matrices are acceptable. Overall, as indicated in Table S1, the environmental aspect (with the weight of 0.523) is obtained as the most important criterion among set of major criteria identified for the main goal of this study (selection of the most relevant bio-façade). Moreover, it is worth mentioning that the final preference scores of the microalgae, green, and water façade are obtained as $0.44,0.36$, and 0.2 , respectively. Thus, it could be concluded that, with comparing the scores achieved by each alternative, the microalgae façade could be considered as the most pertinent candidate.

\section{Conclusions}

Increasing air pollution and its contribution to global warming and climate change have resulted in the introduction of biotic, appropriate, and optimal nature-inspired methods. Although the rate of absorption and control of pollutants is low in the biotic methods, these cheap methods have a lot of advantages. They are useful for other environmental processes, for instance, they do not harm human health and do not require any special technology. Among the proposed biotic methods, microalgae are the living microorganisms capable of photosynthesis and absorption of high pollutants from the air in the fastest time. Integrating them with building façades in enclosures called bioreactors provide a special opportunity for turning walls into photosynthetic surfaces. Integrating microalgae with building façades in enclosures called bioreactors can turn these façades into photosynthetic surfaces. These façades- integrated bioreactors can respond to climate change, improve the inactive thermal performance of the building, transform a typical building into a healthy and vibrant one, and turn its walls into an energy plant. Ultimately, they can turn the walls of a building into a power plant. According to studies, although this method is its infancy and is not cost-effective, its integration with the building façade ensures sustainable sources of energy at the national level, guarantees financial investment contributes to a clean and healthy climate, and promotes symbolic values of society. It is worthy to note that using the AHP method resulted in achieving the higher scores by the microalgae façade among other bio-façades investigated in this study. Therefore, it can be concluded that the microalgae façades could be used as an appropriate type of bio-façade, which can facilitate the sequestration of carbon dioxide in urban areas where gravely suffer from the negative consequences of air pollution.

\section{Acknowledgment}

The authors would like to thank Dr. Alireza Eskandarinejad (Golestan University) for helpful comments on this manuscript.

\section{Author Contributions}

H.R. (Ph.D. student) conceived of the presented idea and wrote the initial version of the manuscript. Z.S (M.A student) encouraged H.R. to investigate the other aspects of the green façade in field of landscape architecture. F.A. (Assistant professor) and F.N. (Assistant professor) provided critical feedback and helped shape of the research, manuscript and supervised the findings of this work. All authors discussed the results and contributed to the final version of the manuscript.

\section{Reference}

1. Ghaleh NM. Environmental assessment of buildings through HQE: Case study: a three-story residential apartment in 5th District of Isfahan. J. Environ. Sci. 2011;37(59):123-134.

2. Mayer H. Air Pollution in Cities. Atmos. Environ. 1999;3:4029-4037.

3. Krzyzanowski M. WHO Air Quality Guidelines for Europe. J. Toxicol. Environ. Health A. 2008;71(1):47-50.

4. Bastanfard M. Controlling air pollution with the use of bio facades (a solution to control air pollution in Tehran). J. Bagh-e Nazar. 2018;15(65):25-40.

5. Azmoode M, Heydari Sh. Quantitative measurement of absorption rate of pollutants from vehicles by Green Walls. J. Environ. Sci. Tech. 2014;16(1):361-370.

6. UNEP. Buildings and climate change: summary for decision-makers. United Nations Environment Programm; 2009.

7. Schnelle KB, Brown CA. Air pollution control technology handbook. United States: CRC Press Boca Raton. FL; 2002; p. 244:21.

8. Lal R. Carbon sequestration. Philosophical Transactions of the Royal Society B: J. Bio. Sci. 2008:363(1492):815-830.

9. Pachauri RK, Allen MR, Barros VR, et al. Climate change 2014: synthesis report. Contribution of Working Groups I, II and III to the fifth assessment report of the Intergovernmental Panel on Climate Change. Switzerland: IPCC; 2014.

10. Zhao B, Su Y. Process effect of microalgal-carbon dioxide fixation and biomass production: a review. Renew. Sustain. Energy Rev. 2014;31(1):121-132.

11. Zhang X. Microalgae removal of CO2 from flue gas. IEA Clean Coal Centre. London: UK; 2015.

12. Elliot S. Cohousing in the Flower City: A Carbon Capture Design. Rochester Institute of Technology: Golisano Institute for Sustainability. Department of Architecture; 2016.

13. Tarnocai C, Canadell J, Schuur E, Kuhry P, Mazhitova G, Zimov $\mathrm{S}$, Soil organic carbon pools in the northern circumpolar permafrost region. Glob. Biogeochem. Cycles. 2009;23(2):1-11.

14. Shukla J, Misra A, Sundar Shyam N. Effect of rain on removal 
of a gaseous pollutant and two different particulate matters from the atmosphere of a city. Math. Com. Model. 2007;48(5): 832-844.

15. Kuwabara B, Auer T, Gouldsborough T, Akerstream T, Klym G. Manitoba Hydro Place Integrated Design Process Exemplar. in 26th Conference on Passive and Low Energy Architecture. Manitoba Hydro Place Integrated Design Consortium. Quebec City: Canada; 2009.

16. Yang J, Yu Q, Gong P. Quantifying air pollution removal by green roofs in Chicago. Atmos. Environ. 2008;42(31):7266-7273.

17. Getter KL, Rowe DB. The role of extensive green roofs in sustainable development. HortSci. 2006;41(5):1276-1285.

18. Oberndorfer E, Lundholm J, Bass B, et al. Green roofs as urban ecosystems: ecological structures, functions, and services. BioSci. 2007;57(10):823-833.

19. Köhler M. Green facades - a view back and some visions. Urb. Ecosys. 2008;11(4):423-436.

20. Ushada M, Murase H. Design of customizable greening material using swarm modeling. Biosys. Eng. 2009;104(2):169-183.

21. Weinmaster M. Are green walls as green as they look? an introduction to the various technologies and ecological benefits of green walls. J. Green Build. 2009;4(4):3-18.

22. Ottelé M, Van Bohemen HD, Fraaij AL. Quantifying the deposition of particulate matter on climber vegetation on living walls. ECo. Eng. 2010;36(2):154-162.

23. Cheng C, Cheung KK, Chu L. Thermal performance of a vegetated cladding system on facade walls. Build. Environ. 2010;45(8): 1779-1787.

24. Perini K, Ottelé M, Haas E, Raiteri R. Vertical greening systems, a process tree for green façades and living walls. Urb. Ecosys. 2013;16(2):265-277.

25. Manso M, Castro-Gomes J. Green wall systems: A review of their characteristics. Renew. Sustain. Energy Rev. 2015;41: 863-871.

26. Perini K, Ottelé M, Fraaij A, Haas E, Raiteri R. Vertical greening systems and the effect on airflow and temperature on the building envelope. Build. Environ. 2011;46(11):2287-2294.

27. Dunnett N, Kingsbury N. Planting green roofs and living walls. Portland: Timber Press Portland, OR; 2008.

28. Pérez G, Rincón L, Vila A, González JM, Cabeza LF. Behavior of green facades in Mediterranean Continental climate. Energy Convers. Manag. 2011;52(4):1861-1867.

29. Kontoleon K, Eumorfopoulou E. The effect of the orientation and proportion of a plant-covered wall layer on the thermal performance of a building zone. Build. Environ. 2010;45(5): 1287-1303.

30. Ottelé M, Perini K, Fraaij A, Haas E, Raiteri R. Comparative life cycle analysis for green façades and living wall systems. Energy Build. 2011;43(12):3419-3429.

31. Fukuzumi Y. Plant growing method for greening wall surfaces. Google Patents; 1996.

32. Gerhardt C, Vale B. Comparison of resource use and environmental performance of green walls with façade greenings and extensive green roofs [dissertation]. School of Architecture. Victoria University of Wellington: New Zealand; 2010.

33. Sharghi E, Mohtashami M. Greenspace in tall buildings with a new approach to nature. Environ. Sci. Tech. 2007;9(4):57-72.
34. Whittaker RH. New concepts of kingdoms of organisms. Sci. 1969;163(3863):150-160.

35. Smith GM. Cryptogamic Botany: Vol. I-Algae and Fungi. Second ed. vol. 1, United Kingdom: McGraw-Hill: JSTOR; 1955.

36. Pearson LC. The diversity and evolution of plants. Florida: CRC Press; 1995.

37. Alabi AO, Bibeau E, Tampier M. Microalgae Technologies \& Processes for Biofuels-bioenergy Production in British Columbia: Current Technology, Suitability \& Barriers to Implementation: Final Report. United Kingdom: British Columbia Innovation Council; 2009.

38. Edwards M. Green algae strategy: end oil imports and engineer sustainable food and fuel. Tempe. Arizona: CreateSpace; 2008.

39. Wolkers H, Barbosa M, Kleinegris D, Bosma R, Wijffels R. Microalgae: The Green Gold of the Future, Large-Scale Sustainable Cultivation of Microalgae for the Production of Bulk Commodities. Netherlands: The Ministry of Economic Affairs AaI; 2011.

40. Elrayies G. Microalgae: prospects for greener future buildings. Renew. Sustain. Energy Rev. 2018;81:1175-1191.

41. Mohammady G, El-Sayed S, Taha M, et al. Chlorella sp. as a Source of Biodiesel and By-Products: An Integral Study of Med-Algae Project; Part A. Int. J. TechnoChem. Res. 2015;1(3): 144-151.

42. Cervera-Sardá R, Gómez-Pioz J, Ruiz-de-Elvira A. Architecture as an Energy Factory: Pushing the Envelope, in Construction and Building Research. Dordrecht: Springer; 2014. p. 209-217.

43. Mata TM, Martins AA, Caetano NS. Microalgae for biodiesel production and other applications: a review. Renew. Sustain. Energy Rev. 2010;14(1):217-232.

44. Ugwu C, Aoyagi H, Uchiyama H. Photobioreactors for mass cultivation of algae. Biores. Tech. 2008;99(10):4021-4028.

45. Proksch G. Growing sustainability - integrating algae cultivation into the built environment. Edinb Archit Res. J. 2013;33(147): 62-75.

46. Cuaresma M, Janssen M, Vílchez C, Wijffels RH. Horizontal or vertical photobioreactors? How to improve microalgae photosynthetic efficiency. Biores. Tech. 2011;102(8):5129-5137.

47. Sudhakar K, Suresh S, Premalatha M. An overview of CO2 mitigation using algae cultivation technology. Int. J. Chem. Res. 2011;3(3):110-117.

48. Duan Y, Shi F. Chapter 2-Bioreactor design for algal growth as a sustainable energy source. In: Fan Shi, eds. Reactor and Process Design in Sustainable Energy Technology. Elsevier; 2014. p. 27-60.

49. Kunjapur A, Eldridge R. Photobioreactor design for commercial biofuel production from microalgae. Ind. Eng. Chem. Res. 2010;49(8):3516-3526.

50. Qiu F. Algae Architecture. Lab report. Architectural Engineering Lab 10; 2014.

51. Marsullo M, Mian A, Ensinas A, et al. Dynamic modeling of the microalgae cultivation phase for energy production in open raceway ponds and flat-panel photobioreactors. Front. Energy Res. 2015;3(1):18-36.

52. Degen J, Uebele A, Retze A, Schmid-Staiger U, Trösch W. A novel airlift photobioreactor with baffles for improved light utilization through the flashing light effect. J. Biotechnol. 
2001;92(2):89-94.

53. Kumar A, Goyal P. Forecasting of daily air quality index in Delhi. Sci. Total Environ. 2011;409(24):5517-5523.

54. Rezazadeh H. Feasibility of building wall design to reduce air pollution using microorganisms: Office building design in Shiraz [Thesis]. Mazandaran: Babolsar; 2018.

55. Sierra E, Acién F, Fernández J, García J, González C, Molina E. Characterization of a flat plate photobioreactor for the production of microalgae. Chem. Eng. J. 2008;138(1):136-147.

56. Slegers P. Scenario studies for algae production [dissertation]. Wageningen: Wageningen University; 2014.

57. Elnokaly A, Keeling I. An empirical study investigating the impact of micro-algal technologies and their application within intelligent building fabrics. Procedia Soc. Behav. Sci. 2016;216:712-723.

58. Xu L, Weathers P, Xiong X, Liu C. Microalgal bioreactors: challenges and opportunities. Eng. Life Sci. 2009;9(3):178-189.

59. Singh R, Sharma S. Development of suitable photobioreactor for algae production-A review. Renew. Sustain. Energy Rev. 2012;16(4):2347-2353.

60. Kim K.-H. A Feasibility Study of an Algae Façade System. Presentation at the International Conference of Sustainable Building. Seoul: South Korea; 2013.

61. Pagliolico SL, Verso VRL, Bosco F, Mollea C, La Forgia C. A novel photo-bioreactor application for microalgae production as a shading system in buildings. Energy Procedia 2017;111: 151-160.

62. Satyanarayana K, Mariano A, Vargas J. A review on microalgae, a versatile source for sustainable energy and materials. Int. J. Energy Res. 2011;35(4):291-311.

63. Consulting L. Advanced Biofuels Study-Strategic Directions for Australia. Sydney: LEK Consulting; 2011.

64. Stephens E, Ross IL, Mussgnug JH, et al. Future prospects of microalgal biofuel production systems. Trends Plant Sci. 2010;15(10):554-564.

65. Öncel S, Köse A, Öncel D. Façade integrated photobioreactors for building energy efficiency, in Start-Up Creation: the smart eco-efficient built environment. London: Elsevier; 2016.

66. Decker M, Hahn G, Harris L. Bio-enabled façade systems-managing complexity of life through emergent technologies. in Proceedings of the 34th eCAADe Conference on Complexity \& Simplicity. Oulu, Finland; 2016.

67. Flynn E. Experimenting with living architecture: a practice perspective. Arch. Res. Quart. 2016;20(1):20-28.

68. Kim J, Todorovic M. Tuning control of buildings glazing's transmittance dependence on the solar radiation wavelength to optimize daylighting and building's energy efficiency. Energy Build.
2013;63:108-118.

69. Sardá R, Vicente C. Case studies on the architectural integration of photobioreactors in building Façades. London: Springer; 2016.

70. Pruvost J, Le Gouic B, Lepine O, Legrand J, Le Borgne F. Microalgae culture in building-integrated photobioreactors: biomass production modelling and energetic analysis. Chem. Eng. J. 2016;284:850-861.

71. Kerner M, Gebken T, Sundarrao I, Hindersin S, Sauss D. Development of a control system to cover the demand for heat in a building with algae production in a bioenergy façade. En. and Build. 2019;184:65-71.

72. Klinthong W, Yang Y, Huang CH, Tan CS. A review: microalgae and their applications in CO2 capture and renewable energy. Aerosol Air Qual Res. 2015;15(2):712-742.

73. Schiller B. This Algae-Powered Building Actually Works; 2014.

74. Genin S, Aitchison J, Allen D. Photobioreactor-based energy sources. Nano and biotech based materials for energy building efficiency. London: Springer; 2016.

75. Bogias P. Algae textile: a lightweight photobioreactor for urban buildings [Master Thesis]. Ontario: School of Architecture. University of Waterloo; 2014.

76. U.S.DOE. National algal biofuels technology roadmap: a technology roadmap resulting from the National algal biofuels workshop. Department of Energy. U.S; 2010.

77. Machado J, Anderson B, Buse T. Green algae photobioreactor. in AIChE Annual Metting. Global challenges for engineering a sustainable future. San Francisco: California. USA: 2013.

78. Suali E, Sarbatly R. Conversion of microalgae to biofuel. Ren. and Sus. En. Rev. 2012;16(6):4316-4342.

79. Rezazadeh H, Kordjamshidi M, Ahmadi F. Experimental Evaluating of CO2 Sequestration Using Building Bio-Façade to Improve Urban Environmental Sustainability. J. Sust. Architect. Urban Design. 2019;7(1):13-28.

80. Rezazadeh H, Kordjamshidi M, Ahmadi F, Eskandarinejad A. Use of double-glazed window as a photobioreactor for CO2 removal from air. Environ. Eng. Res. 2021;26(2):200122.

81. Saaty, TL. A scaling method for priorities in hierarchical structures. J. Math. Psychol. 1977;15(3):234-281.

82. Saaty TL. Decision-making with the AHP: why is the principal eigenvalue necessary. Eur. J. Oper. Res. 2003;145:85-91.

83. Saaty TL, Vargas LG. Prediction, projection and forecasting: applications of the analytic hierarchy process in economics, finance, politics, games and sports. 1st ed. Springer; 1991.

84. Akaa OU, Abu A, Spearpoint M, Giovinazzi S. A group-AHP decision analysis for the selection of applied fire protection to steel structures. Fire Saf. J. 2016;86:95-105. 